\title{
La Tensión entre Materialidad y Discurso: La mirada de Judith Butler sobre el cuerpo
}

\author{
THE TENSION BETWEEN MATERIALITY AND DISCOURSE: JUDITH BUTLER'S NOTION OF BODY
}

Dr. Ariel Martínez (amartinez@psico.unlp.edu.ar) Instituto de Investigaciones en Humanidades y Ciencias Sociales, Universidad Nacional de La Plata (Ciudad de La Plata, Argentina).

\begin{abstract}
This article proposes to analyse the way in which the body is addressed in the philosophical works of Judith Butler. The constructionism that characterizes her initial articles has been widely spread in the contemporary debates about sex and gender diversity, since in those articles she links the body to a discursive ontology that denounces the contingent and unnecessary welding between body -which is considered as the substantial and natural basis of gender and sexuality- and subjective identities. Such an epistemological turn, however, entails the problem of the dissolution of the material body as a strong foundation for various political claims. From this point on, some argumentative lines will be drawn parting from different segments of the author's thought. These lines tend to present a complex notion of the body, clung to the idea of vulnerability.
\end{abstract}

Key words: Judith Butler, body, discourse, materiality, sex.

\section{Resumen}

El presente artículo se propone analizar el modo en que la obra filosófica de Judith Butler aborda el cuerpo. El construccionismo social que caracteriza sus textos iniciales ha cobrado gran difusión en los debates contemporáneos sobre la diversidad sexo-genérica, pues allí la autora vincula al cuerpo a una ontología discursiva que denuncia la soldadura contingente y no necesaria entre cuerpo -pretendida base sustancial y natural del género y la sexualidad- y las identidades subjetivas. Tal giro epistemológico, sin embargo, genera el problema de la disolución del cuerpo material como fundamento sólido para reclamos políticos diversos. A partir de aquí se extraen líneas argumentativas de diferentes segmentos del pensamiento de la autora tendientes a presentar una noción compleja de cuerpo anclada en la idea de vulnerabilidad.

Palabras clave: Judith Butler, cuerpo, discurso, materialidad, sexo.

\section{Introducción}

Aún en la actualidad varias intelectuales feministas no se muestran en conformidad con el alcance de las ideas construccionistas. Fundamentalmente consideran que renunciar a una noción sustancial del cuerpo femenino implica quitar anclaje material a un concepto central respecto a los reclamos políticos. Si la opción es definir a las mujeres como aquellas que portan un cuerpo femenino, emerge la pregunta: ¿cuál es el significado de estas anatomías?, ¿cuál es la conexión entre la anatomía femenina y el concepto de mujer? Y si, como sugiere el constructivismo, tal conexión no existe: ¿en nombre de quién efectuar los reclamos como motor de la acción política? 
El movimiento feminista italiano, por ejemplo, apela al cuerpo a la hora de entender el lugar de la experiencia como articulador de la subjetividad y la política. Lucía Gómez Sánchez y Ana Belén Martín Sevillano (2006) nos muestran el modo en que el feminismo italiano otorga importancia capital al cuerpo no discursivo -no reductible a la representación o a la ideología- como sitio donde se ancla la experiencia real de las mujeres. Instan, entonces, a prestar atención al espectro de síntomas corporales -en el que localizan al deseo, la sexualidad, las fantasías y los miedos-, vectores que debieran integrar cualquier discurso político. Sin dudas, el lenguaje corporal adquiere un lugar notable para la praxis feminista italiana, la que cuestiona y analiza el lugar del cuerpo en términos sociales y políticos, y no en clave psicológica, privada o individual. Es el hecho de tener, y ser en, un cuerpo de mujer lo que debe advenir, entonces, como objeto de la política.

El movimiento de mujeres italianas y su política se basa, claramente, en la diferencia sexual. Desde allí, se repudian los componentes puramente racionales de la identidad propia del humanismo, sobre todo su auto-representación, homogeneidad y estabilidad. Con el objetivo de desplazar a los sujetos y sus prácticas hacia lugares desconocidos, donde es posible hablar en otros términos y donde el pensamiento no tiene ninguna certeza (Irigaray 2009). El movimiento de la diferencia sexual supone, en última instancia, una posición sexuada a partir de la cual adoptar una posición excéntrica que se desplaza desde el interior hacia el exterior de las condiciones sociales y discursivas, siempre bajo la guía de sus propias experiencias encarnadas. Experiencias vividas que, nuevamente, instalan una dimensión del cuerpo más allá del discurso.

\section{Una pequeña fuga del cuerpo Queer}

No hay dudas, tal como sugiere la teoría Queer sedimentada en El género en disputa (2007) de Judith Butler, la ontología depende del discurso. La materialidad del cuerpo, tal como afirma Butler (2008), es histórica, por tanto imposible de ser conceptualizada independientemente de los discursos hegemónicos sobre el género y la sexualidad. El lenguaje es constitutivo y performativo, todo acto significante delimita, bordea y materializa el cuerpo. Sin embargo, aportes recientes de la misma atenúan el grado de radicalidad de sus primeros aportes. A partir de Vida precaria (2006b) es posible afirmar que la innegable vinculación entre cuerpo y discurso no implica, necesariamente, afirmar que la materialidad del cuerpo sea solamente discursiva, tampoco negar al cuerpo como existente real. Implica reconsiderar el estatuto epistemológico del cuerpo. Si en el campo de lo humano la materialidad del cuerpo no permanece independiente de los discursos sociales, y éstos representan e incluso, en cierto sentido, otorgan existencia a los cuerpos, es necesario, entonces, estudiar las condiciones bajo las cuales el cuerpo material se convierte en sexuado.

El pensamiento de Judith Butler ha generado múltiples interpretaciones y debates sobre las categorías de sexo y género, así como también sobre el lugar en el queda inscripto el cuerpo a partir de la vinculación problemática entre ellas. No hay dudas de que la postura de Judith Butler señalada en El género en disputa (2007) indica que el sexo está siempre generizado. Esto implica que el sexo no es sin sus anudamientos constitutivos respecto a las normas de género. Nos dice: “quizás esta construcción denominada 'sexo' esté tan culturalmente construida como el género; de hecho, quizá siempre fue género, con el resultado de que la distinción entre sexo y género no existe como tal" (Butler 2007:55). ¿ ¿No existe distinción entre sexo y género? ¿El sexo es construido absolutamente como género? ¿Todo el sexo es reductible al género? Si el sexo se produce, construye y mantiene a través de las normas de género, entonces ¿qué pasa con el cuerpo? Como Butler misma admite, "tal discurso no es suficiente para argumentar que no hay ningún 'sexo' prediscursivo que actúe como el punto de referencia estable sobre el cual, o en relación con el cual, 
se realiza la construcción cultural del género" (Butler 2008:14). La propia Butler admite que la afirmación escéptica no hay sexo natural es insuficiente.

\section{A la letra de Foucault}

Como ya se ha señalado, Butler apela a Foucault en un intento de interrumpir la lógica causal que localiza al género como el resultado predeterminado del sexo naturalizado. Butler señala que "la producción táctica de la categorización discreta y binaria del sexo esconde la finalidad estratégica de ese mismo sistema de producción al proponer que el 'sexo' es 'una causa' de la experiencia, la conducta y el deseo sexuales. El cuestionamiento genealógico de Foucault muestra que esta supuesta 'causa' es 'un efecto', la producción de un régimen dado de sexualidad, que intenta regular la experiencia sexual al determinar las categorías discretas del sexo como funciones fundacionales y causales en el seno de cualquier análisis discursivo de la sexualidad" (Butler 2007:81-82).

Si el género resulta ser la causa del sexo (y no al revés), entonces el carácter maleable, contingente y político del género se acentúa significativamente. Butler invoca a Foucault para mencionar la aparición histórica de sexo y así socavar la función causal que se le otorga al sexo. En el transcurso de la última mitad de La voluntad de saber (2008) Foucault comienza a girar sobre el despliegue de la sexualidad -esto es: la aparición y expansión de un discurso particular de la sexualidad en los siglos XIX y XX. Inicialmente, esta atención al discurso de la sexualidad sostiene el argumento de Foucault, que rebate la hipótesis represiva y muestra que "el discurso sobre el sexo (...) más que rarificarse se ha multiplicado" (Foucault 2008:53). Su preocupación central se encuentra en el propio despliegue de la sexualidad, en las consecuencias históricas producidas por este discurso. La afirmación más radical del libro aparece en la conclusión cuando Foucault desafía nuestro supuesto respecto a que el discurso de la sexualidad se centra en un objeto particular, pre-discursivo, al que llamamos sexo. Asimismo Foucault refiere a que los objetos del discurso se producen dentro de prácticas discursivas, y aclara que los discursos no emanan de su objeto; muy por el contrario, la existencia de los objetos depende del discurso (Foucault 1970). Esto significa, entonces, que no hay cosa en sí. El sexo -un objeto del discurso- resulta ser "una idea compleja históricamente formada en el interior del dispositivo de sexualidad" (Foucault 2008:145).

Samuel Chambers (2007) afirma que Foucault no intenta desmantelar el sexo a partir de la incorporación del género debido a que ni el género, ni ninguna otra cosa, pueden constituir un principio de causalidad. Esto se debe, fundamentalmente a que, dentro de una trama discursiva no existe principio de causalidad. El discurso en sí, a criterio de Chambers, no puede ser tomado como una causa, pues se trata de la emergencia histórica de prácticas discursivas que se solapan, se intersectan, y a menudo se contradicen. Dentro de estas prácticas discursivas se forman los objetos del discurso y las posiciones de sujeto. Como señala Foucault, "el discurso entendido así no es una forma ideal e intemporal que tuviese además una historia; el problema no consiste, pues, en preguntarse, cómo y por qué ha podido emerger y tomar cuerpo en este punto del tiempo; es, de parte a parte, histórico" (Foucault 1970:198).

A partir de este fragmento no podemos negar la existencia del sexo. Por el contrario, Foucault sostiene que el sexo en sí no existe, y que el sexo es un producto de determinadas prácticas discursivas. Pero de ninguna manera esta última afirmación pretende negar la realidad del sexo, tampoco pretende minimizar esta categoría, más bien es la que permite analizar su importancia histórica y política. La diferencia entre afirmar que el sexo no existe -tesis que, a criterio de Chambers, Butler sugiere-y afirmar que el sexo en sí mismo no existe no es sutil. Podríamos afirmar junto a Foucault que existe el sexo, pero no fuera del 
discurso. Esta diferencia es nodal en su argumento, nos dice: "pero, justamente, es esa idea del sexo la que no se puede admitir sin examen" (Foucault 2008:144).

Chambers asegura, entonces, que la afirmación de Foucault respecto a la emergencia del constructo discursivo sexo revela por qué el sexo no puede servir como una base o principio causal. La unidad entre sexo, género y deseo resulta ser lo que Foucault mismo llama una unidad ficticia. Contra la idea de sexo como fundamento, Foucault ofrece la siguiente tesis: "el sexo, fuera de duda, no es sino un punto ideal hecho necesario por el dispositivo de sexualidad y su funcionamiento" (Foucault 2008:147). Y teniendo en cuenta este argumento, continúa: "no hay que imaginar una instancia autónoma del sexo que produjese secundariamente los múltiples efectos de la sexualidad a lo largo de la superficie de contacto con el poder" (Foucault 2008:147). Chambers sugiere que estas referencias a Foucault demuestran el carácter erróneo de tomar al género como un efecto del sexo. Butler acuerda, claramente, con esta afirmación, pero mediante metalepsis la autora ubica el supuesto efecto -género- en el lugar de la causa -sexo. En este punto, concluye Chambers, es igual de erróneo tomar al sexo como efecto del género. El sexo no es ni causa ni efecto; más bien, es un componente nodal del discurso de la sexualidad.

Estas aclaraciones reciben especial importancia como contrapunto a la tendencia a elidir el sexo como realidad material, lo que impacta en un descuido u olvido de las condiciones o circunstancias de existencia que envuelve a los cuerpos. La preocupación por tematizar el cuerpo como realidad no puramente reductible a los discursos, entonces, no implica negar que "los dispositivos de poder se articulan directamente en el cuerpo -en cuerpos, funciones, procesos fisiológicos, sensaciones, placeres-; lejos de que el cuerpo haya sido borrado, se trata de hacerlo aparecer en un análisis donde lo biológico y lo histórico no se sucederían (...), sino que se ligarían con arreglo a una complejidad creciente (...) [Se trata de] una 'historia de los cuerpos' y de la manera en que se invadió lo que tienen de más material y viviente" (Foucault 2008:144).

Claramente, el rechazo del sexo como causa o fuerza unificadora en Foucault, y aparentemente a diferencia de Butler, lejos de elidir el cuerpo anatómico, insta a una atención detallada de él. La pregunta que nos conduce a un desafío es: ¿cómo podemos deshacernos del sexo como causa o espacio donde se inscribe la verdad del sujeto, y seguir manteniendo un enfoque que otorgue importancia al cuerpo anatómico? En Cuerpos que importan Butler (2008) demuestra que comparte estas preocupaciones. El problema radica, según Chambers, en la forma en que los textos de Butler a veces suponen que, aceptar el carácter históricamente contingente de sexo natural implica centrarse únicamente en la categoría de género. Pues en este punto surge un mal entendido adherido a un constructivismo social mal digerido: lo que se construye no por ello es menos real. Sin embargo, no puede afirmarse sencillamente que, al invertir la causalidad entre sexo y género, y minimizar la importancia del sexo -ya que el sexo ahora aparece erróneamente como epifenómeno del género-, Butler sostenga la tesis que refiere al sexo como absolutamente reductible al género. Butler no rechaza, no niega, no elide, ni borra al cuerpo.

Cuerpos que importan (2008) es, tal vez fue, el mayor esfuerzo de Butler por tematizar el cuerpo. Allí sostiene que toda aproximación al cuerpo culmina por ser una escritura sobre el cuerpo, una materialización del cuerpo solo en, y a través del, lenguaje. En el prefacio a este libro Butler observa que cualquier intento por colocar su atención en la materialidad del cuerpo culmina por reconducirla a otros dominios. Aun así la autora, fiel a la perspectiva instalada en El género en disputa (2007), aunque atenuada, se niega a instalar el cuerpo como dato originario o primigenio, esto es: anterior al discurso -"El cuerpo puesto como anterior al signo es siempre puesto o significado como antes" (Butler 2008:30). Entonces, no podemos tener ningún acceso al cuerpo, excepto a través del discurso. 


\section{La abyección: señal de la materialidad del cuerpo}

En Cuerpos que importan, entonces, el pensamiento de Butler (2008) produce algunas torsiones. Allí la autora reconsidera la radicalidad de algunas aseveraciones realizadas en El género en disputa respecto al sexo. Aquí el foco ya no se encuentra sobre el género en términos de performance corporal. El epicentro para el abordaje del cuerpo sexuado se desplaza hacia la compleja y densa relación entre materialidad y discurso. Dicho de un modo más exacto, "las normas reguladoras del 'sexo' obran de una manera performativa para constituir la materialidad de los cuerpos y, más específicamente, para materializar el sexo del cuerpo" (Butler 2008:18). Tal como la propia autora refiere, sus interrogantes apuntan hacia dos direcciones, a saber: “ ¿Cuáles son las fuerzas que hacen que los cuerpos se materialicen como 'sexuados', y cómo debemos entender la 'materia' del sexo y, de manera más general, la de los cuerpos, como la circunscripción repetida y violenta de la inteligibilidad cultural?” (Butler 2008:14).

Es así que Butler somete a análisis crítico el estatuto ontológico de la materialidad del cuerpo procurando, al igual que en El género en disputa, no quedar adherida a la ontología de la sustancia. Para ello, la autora continúa abordando el asunto en clave foucaultiana al delimitar "la materia de los cuerpos como el efecto de una dinámica de poder, de modo tal que la materia de los cuerpos sea indisociable de las normas reguladoras que gobiernan su materialización y la significación de aquellos efectos materiales" (Butler 2008:19). A partir de aquí, Butler propone "un retorno a la noción de materia, no como sitio o superficie, sino como un proceso de materialización que se estabiliza a través del tiempo para producir el efecto de frontera, de permanencia y de superficie que llamamos materia" (Butler 2008:28). Tales consideraciones constituyen una plataforma analítica a partir de la cual Butler puede forjar el proyecto de analizar dimensiones de la materia sin apelar a un marco de referencia organizado en torno a la noción de sustancia.

Como fuere, a criterio de Butler la materialidad del cuerpo merece mayor espesor conceptual. Su aporte para contribuir a tal modelización teórica consiste en trocar la idea de materia del cuerpo/sexo por la de materialización, como proceso comandado por discursos reguladores y arreglos de poder. Es así que la materialidad del cuerpo sexuado se enmarca en un proceso de producción forzado desde el principio, nos dice Butler. Se trata de una asunción del sexo obligada, impuesta por un aparato regulador que impulsa compulsivamente la heterosexualidad. Esto significa que no es posible escapar a la ley reguladora, por lo que su apropiación forzada es lo que articula inicialmente el cuerpo sexuado en tanto conjunto de acciones movilizadas por esa ley -en términos de la autora, como una "acumulación de citas o referencias (...) que produce efectos materiales" (Butler 2008:34).

Desde este punto de mira, tal carácter citacional constituye la materialización del cuerpo sexuado en términos de una materialidad contorneada. Se trata, en última instancia de una forma ideal que captura y constituye al cuerpo, una morfogénesis que opera en el mismo proceso que permite la emergencia de la subjetividad a partir de un conjunto de proyecciones identificatorias (Butler 2008). Butler apela a la idea de identificación como mecanismo regulado por la norma social. En su formación, el sujeto interioriza la norma mediante identificación. Sin embargo la manifestación del poder establece sitios temidos para la identificación. La identificación posee modelos denegados de antemano, abyectos. Los sujetos, entonces, no se identifican con lo abyecto, zonas marcadas por la amenaza al castigo y por la falta de reconocimiento. Se trata de "fronteras de la vida corporal donde los cuerpos abyectos o deslegitimados no llegan a ser considerados 'cuerpos'” (Butler 2008:38). Entonces podemos delimitar, junto a Butler, la "vinculación de este proceso de 'asumir' un sexo con la cuestión de la identificación y con los medios discursivos que 
emplea el imperativo heterosexual para permitir ciertas identificaciones sexuadas y excluir y repudiar otras" (Butler 2008:19).

Claramente la autora deslinda un régimen heterosexual que no sólo organiza los cuerpos, sino que los materializa en el proceso mismo de construcción. Tal proceso se encuentra comandado por fuertes restricciones en donde se negocian, incluso, los límites de lo humano. En palabras de Butler, "esta matriz excluyente mediante la cual se forman los sujetos requiere pues la producción simultánea de una esfera de seres abyectos, de aquellos que no son 'sujetos', pero que forman el exterior constitutivo del campo de los sujetos. Lo abyecto designa aquí precisamente aquellas zonas 'invivibles', 'inhabitables' de la vida social que, sin embargo, están densamente pobladas por quienes no gozan de la jerarquía de los sujetos, pero cuya condición de vivir bajo el signo de lo 'invivible' es necesaria para circunscribir la esfera de los sujetos" (Butler 2008:19-20).

Las conceptualizaciones butlerianas sobre la materialización del cuerpo sexuado instauran un nuevo horizonte epistemológico a la hora de pensar el asunto. El entrecruzamiento que la autora realiza entre normas corporales y la formación del sujeto en función de la dimensión de lo abyecto sin dudas genera nuevas posibilidades de reflexión y crítica. Butler se esfuerza por delimitar aquellos mecanismos que explican cómo algunas configuraciones o formas de incardinamiento son desterrados del dominio de la inteligibilidad que otorgan las formas ideales que imprime el sexo, esto implica, en términos butlerianos ser desterrados, expulsados, más allá del territorio que delimita lo humano. A partir de aquí, la autora configura un potente armamento analítico a partir del cual es posible imaginar a los cuerpos abyectos con el potencial subversivo de imprimirle "una resignificación radical a la esfera simbólica, (...) desviar la cadena 'de citas' hacia un futuro que tenga más posibilidades de expandir la significación misma de lo que en el mundo se considera un cuerpo valuado y valorable" (Butler 2008:47). Butler nos habla, en esta línea, de política citacional, entendiéndola como "una reelaboración específica que transforme la abyección en acción política (...) representa la performatividad como apelación a las citas con el propósito de dar nueva significación a la abyección (...), para transformarla en desafío y legitimidad. (...) se trata de una politización de la abyección, en un esfuerzo por (...) impulsar su apremiante resignificación. (...) esta estrategia es esencial para crear el tipo de comunidad (...) en la que las vidas queer lleguen a ser legibles, valoradas, merecedoras de apoyo, en la cual la pasión, las heridas, la pena, la aspiración sean reconocidas sin que se fijen los términos de ese reconocimiento en algún otro orden conceptual de falta de vida y de rígida exclusión" (Butler 2008:46-47).

El pensamiento de Butler, entonces, guarda en sí la potencialidad de contribuir desde una reformulación queer de la abyección corporal. A partir de este foco de interés, resulta claro que los aportes del pensamiento de Butler apuntan a borrar cuestiones que puedan inscribirse como configuraciones específicas del cuerpo de las mujeres. Sin embargo, la autora también abre una vía para una posible articulación al reconocer que los cuerpos viven y mueren; comen y duermen; sienten dolor y placer; soportan la enfermedad y la violencia. Claramente su concepción de cuerpo parece desafiar, al menos en parte, la concepción posestructuralista sobre cómo entender el construccionismo, el que, al menos desde ciertas perspectivas, parece negar todo índice de realidad más allá de lo discursivo -lo que equivaldría a afirmar que "la materialidad de los cuerpos es sencilla y únicamente un efecto lingüístico que pueda reducirse a un conjunto de significantes" (Butler 2008:57).

Se trata, nos dice, de "abrir nuevas posibilidades, de hacer que los cuerpos importen de otro modo" (Butler 2008:57) pero sin negar la materialidad de los cuerpos, sino escenificándola de otro modo que no impida pensar condiciones de vulnerabilidad concretas. Incluso menciona, "ciertas formulaciones de la posición 
constructivista radical parecen producir casi obligadamente un momento de reiterada exasperación, porque aparentemente cuando se construye como un idealista lingüístico, el constructivista refuta la realidad de los cuerpos, la pertinencia de la ciencia, los datos supuestos de nacimiento, envejecimiento, enfermedad y muerte" (Butler 2008:30).

\section{Vida invivible}

Judith Butler ha mostrado esfuerzos recientes por pensar el cuerpo de otro modo. Sus producciones actuales esquivan algunas líneas argumentativas interpretadas como una negación del sexo, e implícitamente del cuerpo. A partir de algunas ideas sugeridas en Deshacer el género (2006a), que cobran más fuerza a partir de Vida precaria (2006b), afirma que los cuerpos en su nueva dimensión emergente resultan fundamentales. Tal es así que comienzan a ser motivos justificados para la acción y a servir como elemento constitutivo de una ontología universal (Butler 2014). Butler dirige sus argumentos hacia la profunda vulnerabilidad de los cuerpos (2006b). Los cuerpos pueden ser afectados en múltiples niveles y formas, incluso los cuerpos son radicalmente dependientes. En otras palabras, nuestros cuerpos constantemente insisten, a pesar de nuestra negación a ello, en el hecho de que somos, siempre, con otros.

En Deshacer el género (2006a) Butler instala la idea de vida vivible. Nos dice: "lo más importante es cesar de legislar para todas estas vidas lo que es habitable sólo para algunos y, de forma similar, abstenerse de proscribir para todas las vidas lo que es invivible para algunos" (Butler 2006a:8).

Todo parece indicar, entonces, que una vida vivible es aquella que muestra conformidad de género, es decir que no muestra desviaciones radicales respecto a las normas sexo-genéricas. Por consiguiente, la incompatibilidad respecto con dichas normas puede, incluso, tornar una vida invivible. Esto es, la vida que transcurre en un cuerpo decodificado socialmente como femenino, que se auto identifica como una mujer, que valora las normas de la feminidad, y ama a alguien del sexo opuesto-que a su vez se identifican con las normas de la masculinidad-, resultará mucho más vivible que, por ejemplo, una vida que transcurre en un cuerpo codificado socialmente como varón, pero que se identifica más con las normas de la feminidad que de la masculinidad y al mismo tiempo desea cuerpos e individuos masculinos. Este marco sienta las bases para lo que Butler llama la lucha con la norma.

Esta lucha se ubica en la definición misma de lo humano, donde se articulan los términos que definen qué vida contará como propiamente humana. Butler aborda filosóficamente el cuerpo, y su articulación con las normas, a partir de una fuerte crítica a la idea de autonomía. Butler, tomando como herramienta al psicoanálisis, aborda el tema de manera poco convencional al mostrar cómo el dolor y el duelo siempre trabajan para deshacer la llamada autonomía humana. En el dolor y el duelo estamos al lado, exstáticamente, de nosotros mismos.

Butler, esto es claro, no intenta articular una teoría del dolor ni del duelo. Dolor y duelo sirven para indicar aspectos que resultan nodales en el abordaje de una nueva definición del sujeto en relación con el cuerpo: estar al lado de uno mismo no se deriva de ninguna emoción o experiencia particular, sino de la naturaleza corporal de la existencia misma. Butler señala: "Afrontémoslo. Nos deshacemos unos a otros. Y si no, nos estamos perdiendo algo. Si esto se ve tan claro en el caso del duelo, es tan sólo porque éste ya es el caso del deseo. No siempre nos quedamos intactos. Puede ser que lo queramos, o que lo estemos, pero también puede ser que, a pesar de nuestros mejores esfuerzos, seamos deshechos frente al otro, por el tacto, por el olor, por el sentir, por la esperanza del contacto, por el recuerdo del sentir. Así, cuando 
hablamos de mi sexualidad o de mi género, tal como lo hacemos (y tal como debemos hacerlo) queremos decir algo complicado. Ni mi sexualidad ni mi género son precisamente una posesión, sino que ambos deben ser entendidos como maneras de ser desposeído, maneras de ser para otro o, de hecho, en virtud de otro" (Butler 2006a:38).

Entonces, Deshacer el género no es necesariamente un manifiesto deconstructivista, ya que la autora señala que siempre estamos, a priori, deshechos por nuestros géneros, deshechos por nuestros propios cuerpos. Por un lado, algunas vidas quedan condenadas a la lucha con las normas de género que hacen sus vidas poco vivibles, pero en un nivel más profundo Butler revela el grado en el que estamos, desde el comienzo, deshechos por la sunción del género.

Butler argumenta: "Es a través del cuerpo que el género y la sexualidad se exponen a otros, que se implican en los procesos sociales, que son inscritos por las normas culturales y aprehendidos en sus significados sociales. En cierto sentido, ser un cuerpo es ser entregado a otros aunque como cuerpo sea, de forma profunda, 'el mío propio'”' (Butler 2006a:39-40).

Cuando se trata de nuestros cuerpos emerge la preocupación constante por los demás. Butler señala que, si bien luchamos por los derechos de nuestros cuerpos, también debemos reconocer (al menos implícitamente) que nuestros cuerpos no pueden ser nunca completamente nuestros. Llama a esto la paradoja de la autonomía corporal. Nos dice, "mi cuerpo es y no es mío. Desde el principio es dado al mundo de los otros, lleva su impronta, es formado en el crisol de la vida social; sólo posteriormente el cuerpo es, con una innegable incertidumbre, aquello que reclamo como mío" (Butler 2006a:41). Es así que, sugiere, la política del cuerpo debe ser una política no sólo de los derechos que se adhieren a los cuerpos, sino una política que se ocupan de las normas que hacen la vida vivible.

Entonces, los cuerpos nos deshacen porque su significado excede nuestro alcance. Tal significado permanece en la esfera de las normas de género y de la sexualidad, y tales normas son rearticuladas en la cultura, en la sociedad, en la política. Las políticas de Butler enfocan el funcionamiento de la norma, no porque ella ignore los cuerpos, sino precisamente porque reconoce el papel que las normas deben jugar en cualquier política del cuerpo. Señala, "cuando luchamos por nuestros derechos no estamos sencillamente luchando por derechos sujetos a mi persona, sino que estamos luchando para ser concebidos como personas" (Butler 2006a:56). Es así que la lucha para hacer posible una vida vivible no puede borrar al cuerpo. Mientras que tal política concede que el cuerpo es nuestro -es decir, que uno tiene derecho a él-, esta política debe insistir en que el cuerpo también resulta no ser del todo nuestro. Y tal política debe centrar la atención en aquellas normas que hacen la vida vivible para algunos cuerpos e invivible para otros. En palabras de Butler: "cuando hablamos de derechos sexuales no estamos simplemente hablando de derechos relacionados con nuestros deseos individuales, sino de las normas de las que depende nuestra propia individualidad" (Butler 2006a:58). Así es como Butler reconoce la relevancia de una causa política que reivindique los derechos sexuales, pero al mismo tiempo se niega a tomar al sujeto político como algo dado, previo, como punto de partida para la política, ya que la política debe estar relacionada, desde este punto de vista, con la producción de ese sujeto.

Esta insistencia constante en la relación entre los cuerpos y las normas nos conduce hacia lo que, tal vez, es la definición más notable de cuerpo que Butler realiza: "el cuerpo es aquello que puede ocupar la norma en una miríada de formas, que pueden exceder la norma, volver a dibujar la norma y exponer la posibilidad de la transformación de realidades a las cuales creíamos estar confinados" (Butler 2006a:306-307). 


\section{A modo de conclusión: hacia la idea de Quiasmo}

En suma, los últimos aportes de Butler en torno al cuerpo se alejan de su intento inicial por borrar el sexo, pues su interés ya no transcurre por colapsar su diferencia respecto al género. A pesar de que, aún en sus últimas producciones, Butler no negaría que cualquier aporte en función de la categoría de género debe renunciar a la noción de sexo como algo natural. Incluso también destacaría que el género no debe ser reducido al sexo, tampoco tomar al sexo como un terreno causal para el anterior. Sin embargo, esa explicación debe al mismo tiempo evitar la trampa de la inversión de esa causalidad. Generizar el sexo no significa, necesariamente, eliminar el sexo. Es posible, si tenemos en cuenta los aportes recientes de Butler, una teoría del sexo/género que sitúe la relación entre sexo y género al mismo tiempo que toma al sexo como una construcción discursiva de gran alcance, con importantes efectos sociales y políticos. Entonces, el cuerpo adviene como un sitio que permite y limita la acción política. Nuevamente, esto no significa que el cuerpo pueda o deba ser reducido al discurso. De hecho, el cuerpo excede el discurso y reelabora las normas que lo limitarían. Resulta interesante evitar un idealismo que reduce toda la materia a los signos, pero sin caer en un realismo extremo que separa radicalmente la materia de los signos. La primera posición ignora el hecho de que la materia no puede ser creada por el discurso. La segunda pasa por alto el hecho de que la materia es y sólo se materializa a través del discurso. Ambas siguen ciegas ante la simple verdad de que todos los signos son en sí mismos materiales (Butler 2008).

Si bien Butler rechaza cualquier teoría construida sobre una idea de cuerpo subsidiaria a una ontología de la sustancia, no puede elidir algo fundamental acerca de los cuerpos: los cuerpos, de la última Butler, son vulnerables. Un cuerpo depende de los demás y, al mismo tiempo, es objeto de posibles peligros que provienen de los demás. A través de nuestro cuerpo siempre permanecemos expuestos a los demás, y nuestra vulnerabilidad nos ata a los otros (Butler 2006b). Sólo en este sentido encontramos algo primordial sobre el cuerpo, algo fundamental, innegable, una ontología universal (Butler 2014).

En pocas palabras, existen líneas teóricas en el pensamiento de Butler donde el cuerpo posee dimensiones no tenidas en cuenta en las lecturas canónicas. La autora ha prestado atención al dolor y la vulnerabilidad de los cuerpos desde el inicio de su trabajo, sin embargo estas líneas quedan ocluidas por otros segmentos más pregnantes de su pensamiento, por tanto no son tenidas en cuenta por ciertas líneas de la teoría feminista a partir de las cuales se le efectúan fuertes críticas.

Las críticas que apuntan a Butler se preguntan por la materialidad del cuerpo, porque se centran en lo que su teoría de género le hace al sexo. Los críticos de Butler, tanto implícita como explícitamente, se preocupan por la primacía y la materialidad del sexo, y la base epistemológica que proporciona. La preocupación puede figurarse del siguiente modo: si el sexo es reductible en su totalidad al género, entonces ¿no hay tal cosa como sexo? Y si todo es sexo, entonces ¿el cuerpo ya no importa? Irónicamente, una de sus obras más notables se titula Bodies that matter [Cuerpos que importan (2008)] contiene la afirmación directa de que los cuerpos sí importan. Sin embargo la palabra matter tiene claramente un doble significado. Como en dicho texto Butler articula una teoría acerca de la materialización de los cuerpos, muestra cómo los cuerpos matter en el sentido de llegar a ser materializados a través del discurso. Las críticas apuntan, más que nada, a saber cómo dentro de una teoría constructivista radical del género, el cuerpo matter en el sentido de ser importante, demostrando ser significativo tanto para la teoría como para la política. Responder a esta inquietud sobre el segundo sentido de matter requiere una exploración más allá de lo que Butler ha previsto expresamente para el papel del sexo en su teoría. Como fuere, el hecho de que el sexo no sea considerado como la base ontológica del género, no implica que el sexo simplemente desaparezca. 
Entender el sexo a partir de los términos de género no equivale a afirmar que no hay ninguna diferencia entre sexo y género. El género se vive a través del cuerpo, y las normas de género no son inherentemente corporales -esto significa que reducir el sexo al género significa, en cierto modo, acabar con el cuerpo. Entonces, si bien sólo entendemos al sexo a través de las normas de género, ello no conduce directamente a la postura que afirma que no hay sexo. Del mismo modo que nacemos en un mundo en el que ya operan las normas de género, también nacemos en un cuerpo... un cuerpo sexuado.

Cabe señalar, finalmente, la figura del quiasmo que la propia Butler introduce para pensar la compleja vinculación entre materialidad y lenguaje implicada en el análisis del cuerpo. Mabel Campagnoli (2013) reconoce las críticas que ha recibido la teoría performativa de la identidad de género de Judith Butler, respecto de no tomar en consideración al cuerpo. Si las acusaciones apuntan a que Butler postula una abstracción que captura al cuerpo, propia de todo idealismo, o fundacionalismo discursivo o lingüístico. Es así que la noción de quiasmo se instala como recurso que permite ver que su teoría no es desencarnada. Campagnoli detecta lo que en el recorrido aquí propuesto se ha señalado, esto es: en Cuerpos que importan (2008) Butler reformula su línea teórica, al menos parcialmente, presente en El género en disputa (2007) respecto a la materialidad de los cuerpos como puramente discursiva. La reformulación refiere a introducir la dinámica de poder presente en el proceso de materialización, lo que torna a la materia de los cuerpos indisociable de las normas reguladoras que gobiernan su materialización y la significación de aquellos efectos materiales. Campagnoli advierte que si bien Butler no refiere a la noción de quiasmo para organizar tal reformulación, sí retoma la noción de carne de Merleau-Ponty. Es así que los vínculos entre cuerpo y discurso varían de tal modo que lenguaje y la materialidad no parecen, ya, enfrentarse de manera inconciliable, pues "el lenguaje es y se refiere a aquello que es material, y lo que es material nunca escapa del todo al proceso por el cual se le confiere significación. Pero, si bien el lenguaje no se opone a la materialidad, tampoco es posible reducir sumariamente la materialidad a una identidad con el lenguaje" (Campagnoli 2013:50).

Es en la particularidad de esta relación donde se localiza el quiasmo, noción utilizada por Butler en Lenguaje, poder e identidad (2004). Allí afirma, nos muestra Campagnoli, que "la relación entre el habla y el cuerpo es un quiasmo. El habla es corporal, pero el cuerpo a veces excede el habla; y el habla permanece irreductible a los sentidos corporales de su enunciación" (Butler 2004:251).

Más explícitamente, Butler nos dice: "Suelo considerar la relación entre cuerpo y discurso como un 'quiasmo'. Esta figura retórica procura comprender de qué manera dos entidades se superponen sin ser coextensas entre sí (...). El cuerpo cobra forma y figura en el contexto de ciertas normas discursivas (...) que lo 'con-forma' activamente. Pero al cuerpo no puede reducírselo a las distintas formas que adopta, ya que por debajo de su desarrollo y transmutación hay algo continuo (...). Nunca nos encontramos con un cuerpo 'crudo' o puro, ni siquiera en momentos extremos de placer o dolor (...). Ambos pueden quebrar la forma, pero no por eso dejan de relacionarse con ella (...) el cuerpo y la forma discursiva a través de la cual se materializa son indisociables, pero al mismo tiempo no se reducen uno al otro" (Butler 2008:83).

Finalmente cabe destacar que este postulado que implica una torsión clave se encuentra presente en uno de los segmentos iniciales de su obra, cuando afirma que: "Esto no significa que, por un lado, el cuerpo sea sencillamente materia lingüística o, por el otro, que no influya en el mensaje. En realidad influye en el lenguaje todo el tiempo. La materialidad del lenguaje, o más precisamente del signo mismo que procura denotar 'materialidad', sugiere que no todo, incluyendo la materialidad, es desde siempre lenguaje. Por el contrario, la materialidad del significante (una 'materialidad' que comprende tanto los signos como su eficacia significativa) implica que no puede haber ninguna referencia a una materialidad pura salvo a través 
de la materialidad. Por lo tanto, no es que uno no pueda salirse del lenguaje para poder captar la materialidad en sí misma y de sí mismo; antes bien, todo esfuerzo por referirse a la materialidad se realiza a través de un proceso significante que, en su condición sensible, es siempre ya material. En este sentido, pues, el lenguaje y la materialidad no se oponen, porque el lenguaje es y se refiere a aquello que es material, y lo que es material nunca escapa del todo al proceso por el cual se le confiere significación" (Butler 2008:110).

\section{Nota}

El autor es director del proyecto "Identidad de género y cuerpo. Entrecruzamientos conceptuales en el feminismo psicoanalítico norteamericano de finales del siglo XX" (Código PPID/H017), acreditado y subsidiado por la Universidad Nacional de La Plata. Período agosto 2014 - septiembre 2016.

\section{Bibliografía}

Butler, J. 2004. Lenguaje, poder e identidad. Madrid: Síntesis.

Butler, J. 2006a. Deshacer el género. Barcelona: Paidós.

Butler, J. 2006b. Vida precaria. El poder del duelo y la violencia. Buenos Aires: Paidós.

Butler, J. 2007. El género en disputa. El feminismo y la subversión de la identidad. Barcelona: Paidós.

Butler, J. 2008. Cuerpos que importan. Sobre los límites materiales y discursivos del 'sexo'. Buenos Aires: Paidós.

Butler, J. 2014. Vida precaria, vulnerabilidad y ética de cohabitación. En: B. Saez Tajafuerce (Ed.). Cuerpo, memoria y representación. Barcelona: Icaria, pp. 7-80.

Campagnoli, M. 2013. La noción de quiasmo en Judith Butler: para una biopolítica positiva. Nómadas 39 : 47-61. http://www.scielo.org.co/scielo.php?pid=S0121-75502013000200004\&script=sci_arttext

Chambers, S. 2007. 'Sex' and the problem of the body: reconstructing Judith Butler's theory of sex/gender. Body \& Society 13(4): 47-75. doi: 10.1177/1357034X07085537

Foucault, M. 1970. La arqueología del saber. México: Siglo XXI.

Foucault, M. 2008. La voluntad de saber. Historia de la sexualidad Vol 1. México: Siglo XXI.

Gómez Sánchez, L. y Martín Sevillano, A. B. 2006. Experience, subjectivity and politics in the Italian feminist movement: redefining the boundaries between body and discourse. European Journal of Women's Studies 13(4): 343-355. doi: 10.1177/1350506806068653

Irigaray, L. 2009. Ese sexo que no es uno. Madrid: Akal.

Recibido el 15 Jul 2015

Aceptado el 23 Oct 2015 